\title{
Simulation Study of Sensitivity Performance of MEMS Capacitive Bending Strain Sensor for Spinal Fusion Monitoring
}

\author{
Muhammad Irsyad Abdul Mokti and Inzarulfaisham Abd Rahim \\ School of Mechanical Engineering, University Sains Malaysia, Engineering Campus, Seberang Perai Selatan, Penang, \\ 14300 Nibong Tebal, Malaysia \\ Correspondence should be addressed to Muhammad Irsyad Abdul Mokti, miam09_em0655@student.usm.my
}

Received 26 July 2012; Accepted 11 November 2012

Academic Editor: Aiguo Song

Copyright ( 2012 M. I. Abdul Mokti and I. Abd Rahim. This is an open access article distributed under the Creative Commons Attribution License, which permits unrestricted use, distribution, and reproduction in any medium, provided the original work is properly cited.

\begin{abstract}
This study evaluates the sensitivity of microelectromechanical system (MEMS) capacitive bending strain sensor with a double layer cantilever designed to meet the requirements of spinal fusion monitoring. The cantilever structure of the sensor consists of two parallel substrate plates which constitute the electrodes, attached to an anchor made of silicon dioxide. The sensor was able to monitor bending strain value ranging from 0 to $1000 \mu \varepsilon$. In order to evaluate the sensitivity of the sensor, parametric study was carried out by varying electrode gap, anchor length, and dielectric coverage between the electrodes. The nominal capacitive strain sensor for various applications has sensitivity ranging from $255 \mathrm{aF} / \mu \varepsilon$ to $0.0225 \mathrm{pF} / \mu \varepsilon$. An increase in the sensitivity was observed on reducing the electrode gap and the anchor length and increasing the dielectric coverage, resulting in a highest sensitivity value of $0.2513 \mathrm{pF} / \mu \varepsilon$. It was also observed that dielectric constant has a significant effect on the sensitivity behavior of the sensor.
\end{abstract}

\section{Introduction}

MEMS capacitive based sensor has been widely used and has a variety of applications that includes measurement of pressure, gas flow, force, position, displacement, chemical, vacuum, tactile, and $\mathrm{RH}$ monitoring. When compared to piezo based sensors, capacitive sensors have several advantages such as high sensitivity, low power consumption, better temperature performance, and less sensitivity to drift [1]. By varying the variable in the capacitance equation the capacitance output of the sensor can be manipulated.

Several types of capacitive sensors have been developed for strain monitoring applications. A capacitive strain sensor for automobile tire strain monitoring, having a comb drive structure, was developed by Matsuzaki and Todoroki [2]. The sensor was located on the flexible substrate. When subjected to strain, the gap between the comb drive electrodes increased causing the difference in values of capacitance. They observed that sensitivity of the sensor varied with design and the highest sensitivity value obtained was at $45.71 \mathrm{aF} / \mu \varepsilon$. Suster et al. [3] also developed a MEMS capacitive strain sensor with a comb drive structure for rotating shaft surface strain monitoring. When strain was induced, the area of the overlap electrodes changed significantly leading to change in the capacitance output of the sensor. This sensor exhibited higher sensitivity at $255 \mathrm{aF} / \mu \varepsilon$. Aebersold et al. [4] in their work studied the MEMS capacitive bending strain sensor for spinal fusion monitoring. They developed a sensor having a comb drive structure, with electrodes made from heavily doped silicon.

When bending occurred, the gap and also the overlap area of the electrode changed, resulting in the change in capacitance reading. The sensitivity of this sensor was $2.94 \mathrm{fF} / \mu \varepsilon$ for strain value between 0 to $1000 \mu \varepsilon$. Similarly, Lin et al. [5] developed a MEMS capacitive bending strain sensor for spinal fusion monitoring but having different sensor structure. The sensor had a cantilever beam structure with two layers. When bending strain was induced, the gap between the electrodes changed, which led to the capacitance change for bending strain reading. The sensor exhibited highest sensitivity of $0.02 \mathrm{pF} / \mu \varepsilon$ between 0 to $1000 \mu \varepsilon$.

A comparative study of different capacitive strain sensors with their sensitivity values has been summarized in Table 1 . 
TABLE 1: Capacitive strain sensor comparison.

\begin{tabular}{|c|c|c|c|c|}
\hline Application & $\begin{array}{l}\text { Automobile tire strain } \\
\text { monitoring }\end{array}$ & $\begin{array}{l}\text { Rotating shaft surface } \\
\text { strain }\end{array}$ & $\begin{array}{l}\text { Spinal fusion } \\
\text { monitoring }\end{array}$ & $\begin{array}{l}\text { Spinal fusion } \\
\text { monitoring }\end{array}$ \\
\hline Design structure & Comb drive & Comb drive & Comb drive & Double layer cantilever \\
\hline $\begin{array}{l}\text { Sensing } \\
\text { mechanism }\end{array}$ & $\begin{array}{l}\text { Electrodes gap } \\
\text { manipulation using } \\
\text { flexible epoxy resin }\end{array}$ & $\begin{array}{l}\text { Electrodes overlap area } \\
\text { manipulation }\end{array}$ & $\begin{array}{l}\text { Electrodes gap and } \\
\text { overlap area } \\
\text { manipulation }\end{array}$ & $\begin{array}{l}\text { Electrodes gap } \\
\text { manipulation }\end{array}$ \\
\hline Sensitivity & $45.71 \mathrm{aF} / \mu \varepsilon$ & $255 \mathrm{aF} / \mu \varepsilon$ & $2.94 \mathrm{fF} / \mu \varepsilon(0-1000 \mu \varepsilon)$ & $0.02 \mathrm{pF} / \mu \varepsilon(0-1000 \mu \varepsilon)$ \\
\hline $\begin{array}{l}\text { Nominal } \\
\text { capacitance }\end{array}$ & $3.4-34.7 \mathrm{pF}$ & $440 \mathrm{fF}$ & $8.01 \mathrm{pF}$ & $18-43 \mathrm{pF}$ \\
\hline Output pattern & Nonlinear & Linear & Nonlinear & Nonlinear \\
\hline Minimum gap & $0.5 \mathrm{~mm}$ & $2 \mu \mathrm{m}$ & $25 \mu \mathrm{m}$ & $3 \mu \mathrm{m}$ \\
\hline Sensor material & $\begin{array}{l}\text { Flexible substrate } \\
\text { (copper with polyimide) } \\
\text { on ultra flexible epoxy } \\
\text { resin }\end{array}$ & $\begin{array}{l}\text { SOI wafer for substrate } \\
\text { and device layer, } \\
\text { aluminum electrode }\end{array}$ & $\begin{array}{l}\text { Silicon boron doped } \\
\text { very low resistivity } \\
\text { anodic bonding to } \\
\text { borosilicate glass }\end{array}$ & $\begin{array}{l}\text { Borosilicate glass, silicon } \\
\text { p-type, gold electrodes }\end{array}$ \\
\hline
\end{tabular}

The comb drive structure can be designed to manipulate the gap, and also the overlap area of the electrodes to induce the capacitance change. It is also the most commonly used structure for sensor. However, the cantilever beam structure designed by Lin et al. [5] showed highest sensitivity when compared to comb drive structure. In this study, the cantilever beam structure design has been utilized owing to its higher sensitivity.

The primary objective of this work was to evaluate the sensitivity of MEMS capacitive bending strain sensor, designed using cantilever beam structure. Equation (1) demonstrates that the capacitance output can be increased by reducing the electrode gap, increasing the overlap area of the electrodes or by using a high dielectric coefficient material between the electrodes. For any sensor, these parameters are of significant importance and are highly dependent on the structural design of the sensor. In case of cantilever beam structure design, actuated due to bending forces, all these parameters can be applied to increase the capacitance output. However, the influence of these parameters on the sensitivity of the sensor to the bending strain is not well established. Therefore this study was carried out to ascertain the relationship between these parameters on the sensitivity of the designed sensor. The present sensitivity enhancement study was accomplished by varying three parameters, namely, electrode gap, anchor length, and the dielectric material. By changing these parameters the capacitance output of the sensor and its sensitivity when bending strain developed can be examined. Simulation using finite element software, CoventorWare 2008, was also carried out and the results are compared with those of analytical output.

\section{Sensor Design}

The sensor was designed to meet the requirements of spinal fusion monitoring. Spinal fusion is a medical procedure, wherein the lumbar vertebrate causing pain to the patient needs subsequent fixation of titanium rod to facilitate
TABLE 2: Sensor requirements.

\begin{tabular}{lc}
\hline $\begin{array}{l}\text { Range of anticipated strain } \\
\text { Sensing element }\end{array}$ & $0-1000 \mu \varepsilon$ \\
Sensor dimension & Bending strain \\
Wireless telemetry application & $\begin{array}{c}\text { Maximum of } 10 \mathrm{~mm} \times 2 \mathrm{~mm} \\
\text { Low power requirement, } \\
\text { capacitive is preferable }\end{array}$ \\
\hline
\end{tabular}

healing [6, 7]. The designed sensor will be located on the titanium rod fixation and monitors the bending strain change during the healing process. Kanayama et al. [8] in their work concluded that bending strain was the main loading anticipated by the titanium rod. Gibson [9] showed that the maximum strain value of the rod was nearly $1000 \mu \varepsilon$. In order to be able to mount on the rod and other wireless circuitry, Aebersold et al. [4] and Lin et al. [5] suggested the maximum dimension of the sensor to be around $10 \mathrm{~mm} \times$ $2 \mathrm{~mm}$ (width $\times$ length). Table 2 summarizes the requirement of the sensor for spinal fusion monitoring.

In this work, the sensor designed has three layers. The substrates at the bottom and top layer are the electrodes built from heavily doped silicon for better conductivity. The gap between these electrodes was determined using the anchor made from silicon dioxide. This gap was varied to study the capacitance output and also the sensitivity. The anchor length was also varied as it would affect the opening of the electrodes when bending occurred. Finally, the effect of dielectric material with three different percentage configurations was also determined. The sensor designed had width of $2 \mathrm{~mm}$. The schematic diagram of the sensor in Figure 1 shows the three parameters used.

\section{Theory}

The sensor actuation can be modeled as a simple cantilever beam bending, which has one fixed end and a suspended free end on the other side as shown in Figure 2. 
TABLE 3: Specific values used in the calculation for all analysis parameters.

\begin{tabular}{|c|c|c|c|c|c|c|c|}
\hline Analysis parameter & $x_{1}(\mathrm{~mm})$ & $x_{2}(\mathrm{~mm})$ & $L(\mathrm{~mm})$ & $l_{0}(\mathrm{~mm})$ & $l_{1}(\mathrm{~mm})$ & $l_{2}(\mathrm{~mm})$ & $l_{3}(\mathrm{~mm})$ \\
\hline \multicolumn{8}{|l|}{ Gap study } \\
\hline \multicolumn{8}{|l|}{$1.5 \mu \mathrm{m}$} \\
\hline $3 \mu \mathrm{m}$ & 8.1 & 2.1 & 8.2 & 0.1 & 8.1 & 2.1 & 1.1 \\
\hline \multicolumn{8}{|l|}{$5 \mu \mathrm{m}$} \\
\hline \multicolumn{8}{|l|}{ Anchor length } \\
\hline $0.5 \mathrm{~mm}$ & 8.1 & 0.6 & & & & & \\
\hline $1 \mathrm{~mm}$ & 8.1 & 1.6 & 8.2 & 0.1 & 8.1 & 2.1 & 1.1 \\
\hline $1.5 \mathrm{~mm}$ & 8.1 & 2.1 & & & & & \\
\hline \multicolumn{8}{|l|}{ Dielectric coverage } \\
\hline \multirow[t]{2}{*}{$33 \%$} & Air: 6.1 & Air: 2.1 & & & & & \\
\hline & $\mathrm{SiO}_{2}: 8.1$ & $\mathrm{SiO}_{2}: 6.1$ & & & & & \\
\hline \multirow[t]{2}{*}{$66 \%$} & Air: 4.1 & Air: 2.1 & 8.2 & 0.1 & 8.1 & 2.1 & 1.1 \\
\hline & $\mathrm{SiO}_{2}: 8.1$ & $\mathrm{SiO}_{2}: 4.1$ & & & & & \\
\hline \multirow[t]{2}{*}{$100 \%$} & Air: - & Air: - & & & & & \\
\hline & $\mathrm{SiO}_{2}: 8.1$ & $\mathrm{SiO}_{2}: 2.1$ & & & & & \\
\hline
\end{tabular}

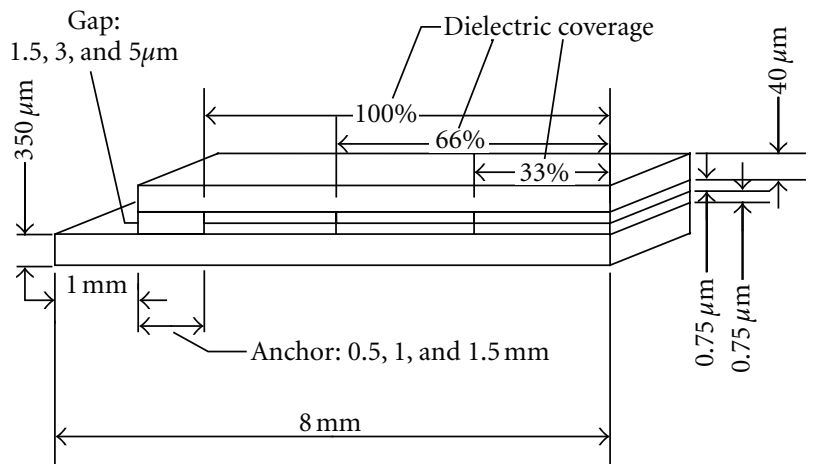

FIGURE 1: Schematic diagram of the sensor with three parameters for sensitivity enhancement.

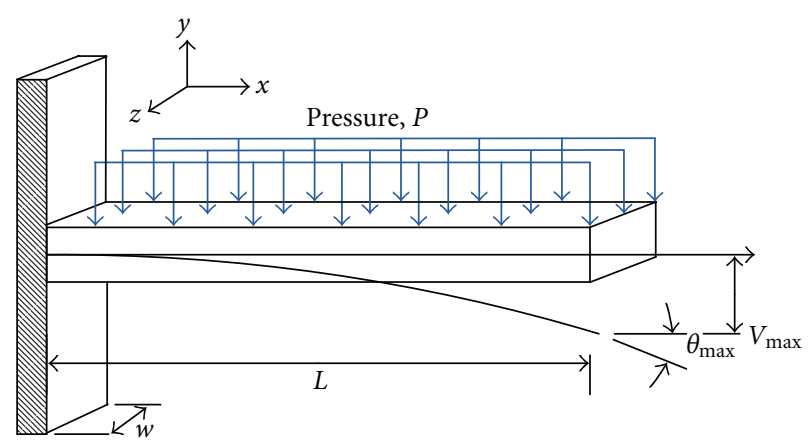

FIGURE 2: Load distribution and the cantilever bending schematic diagram. as

The capacitance of the two electrode plate can be written

$$
C=\frac{\varepsilon_{0} \varepsilon_{r} A}{d} .
$$

The relationship for a simple beam bending can be determined from the beam bending theory and the flexure formula as [10]

$$
\begin{gathered}
\varepsilon=\frac{\sigma}{E}, \\
\sigma_{\max }=\frac{y_{\max } M}{I} .
\end{gathered}
$$

Moment along $x$ was given by

$$
M_{x}=\frac{P(L-x)^{2}}{2} w,
$$

where $w$ is the beam width and $P$ is evenly distributed pressure load. Slope, $\theta(x)$, and deflection, $V(x)$ along $x$-axis were given by

$$
\begin{aligned}
\theta(x) & =\frac{P w x}{6 E I}\left(x^{2}-3 x L+3 L^{2}\right), \\
V(x) & =\frac{P w x^{2}}{24 E I}\left(6 L^{2}-4 x L+x^{2}\right) .
\end{aligned}
$$

The sensor was modelled on the simple cantilever beam. The beam was fixed at one end, and bending occurred at the free end. During bending, the lower electrode of the sensor also bends along with the cantilever beam. Meanwhile, the top electrode of the sensor, fixed along point $x=l_{3}$ to $x=l_{2}$, will have a tangent deflection [11]. The top electrode of the sensor would bend in a tangent form starting at point $x=l_{2}$. The mechanism would increase the gap of the electrodes as the bending occurred. The deflection of the sensor model is illustrated in Figure 3.

Tangent deflection equation at point $x=l_{2}, V_{d}(x)$ along $x$-axis can be written as

$$
V_{d}(x)=\theta\left(l_{2}\right) x+B
$$




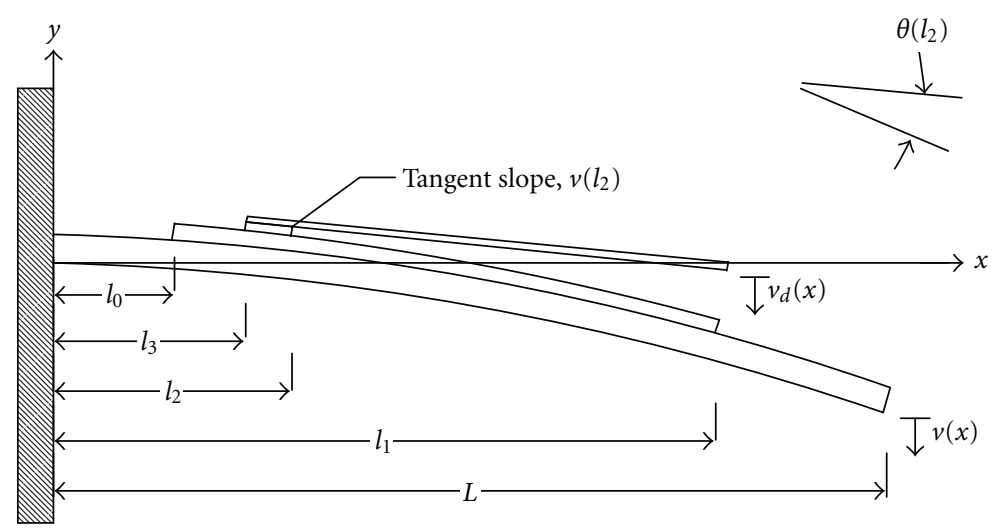

FIGURE 3: Schematic diagram for sensor model deflection.

where $B$ is a constant that can be obtained using a boundary condition $[5,11]$. When the sensor model bends, the tangent deflection line at point $x=l_{2}, V_{d}(x)$ was equal to the deflection of the lower layer of the sensor, $V(x)$, one has

$$
\begin{gathered}
V_{d}\left(l_{2}\right)=V\left(l_{2}\right)=\theta\left(l_{2}\right) l_{2}+B, \\
B=V\left(l_{2}\right)-\theta\left(l_{2}\right) l_{2} .
\end{gathered}
$$

Using (4) and (5), the constant $B$ can be obtained as

$$
B=\frac{P w}{24 E I}\left(8 l_{2}^{3} L-6 l_{2}^{2} L^{2}-3 l_{2}^{4}\right)
$$

$B$ then is substituted into (5) and gives us

$$
\begin{array}{r}
V_{d}(x)=\frac{P w}{24 E I}\left[\left(4 l_{2}^{3}-12 l_{2}^{2} L+12 l_{2} L^{2}\right) x\right. \\
\left.+\left(8 l_{2}^{3} L-6 l_{2}^{2} L^{2}-3 l_{2}^{4}\right)\right] .
\end{array}
$$

Thus, the difference in deflection or gap between the tangent deflection line at point $x=l_{2}, V_{d}(x)$, and the lower layer of the sensor model beam $V(x)$ along $x$-axis can be written as $D(x)$ and can be given by the following equation:

$$
D(x)=V(x)-V_{d}(x)
$$

$D(x)$ is integrated for $x=x_{1}$ and $x=x_{2}$ to acquire the average value of the gap along $x$ axis that corresponds to pressure load, $P$ applied, one has

$$
\begin{aligned}
\int D(x)= & \frac{P w}{24 E I\left(x_{1}-x_{2}\right)} \\
\times & {\left[\left(2 x^{3} L^{2}-x^{4} L+\frac{x^{5}}{5}\right)-x^{2}\left(2 l_{2}^{3}-6 l_{2}^{2} L+6 l_{2} L^{2}\right)\right.} \\
& \left.\quad-x\left(8 l_{2}^{3} L-6 l_{2}^{2} L^{2}-3 l_{2}^{4}\right)\right]_{x_{2}}^{x_{1}},
\end{aligned}
$$

$$
\begin{aligned}
& D(x)= \frac{P w}{24 E I\left(x_{1}-x_{2}\right)} \\
& \times {\left[\left(2 x_{1}^{3} L^{2}-x_{1}^{4} L+\frac{x_{1}^{5}}{5}\right)-\left(2 x_{2}^{3} L^{2}-x_{2}^{4} L+\frac{x_{2}^{5}}{5}\right)\right.} \\
& \quad-\left(x_{1}^{2}-x_{2}^{2}\right)\left(2 l_{2}^{3}-6 l_{2}^{2} L+6 l_{2} L^{2}\right) \\
&\left.-\left(x_{1}-x_{2}\right)\left(8 l_{2}^{3} L-6 l_{2}^{2} L^{2}-3 l_{2}^{4}\right)\right], \\
& D=\frac{\varepsilon}{12 y_{\max }\left(L-l_{0}\right)^{2}\left(x_{1}-x_{2}\right)} \times\left[\left(2 x_{1}^{3} L^{2}-x_{1}^{4} L+\frac{x_{1}^{5}}{5}\right)-\left(2 x_{2}^{3} L^{2}-x_{2}^{4} L+\frac{x_{2}^{5}}{5}\right)\right. \\
& \quad-\left(x_{1}^{2}-x_{2}^{2}\right)\left(2 l_{2}^{3}-6 l_{2}^{2} L+6 l_{2} L^{2}\right) \\
&\left.\quad-\left(x_{1}-x_{2}\right)\left(8 l_{2}^{3} L-6 l_{2}^{2} L^{2}-3 l_{2}^{4}\right)\right] .
\end{aligned}
$$

Solving (2), (3), and (11) gives (12) used for calculating the average electrodes gap for sensor. The value for $x_{1}$ and $x_{2}$ depends on the analysis study for sensitivity enhancement. Table 3 gives the typical values used for the analysis.

The total capacitance for electrode gap and anchor length analysis, $C_{T}$ was given by

$$
C_{T}=C_{1}+C_{2}, \quad \text { where } C_{1}=\frac{\varepsilon_{0} \varepsilon_{r} A_{1}}{d} ; \quad C_{2}=\frac{\varepsilon_{0} \varepsilon_{r} A_{2}}{d+D} .
$$




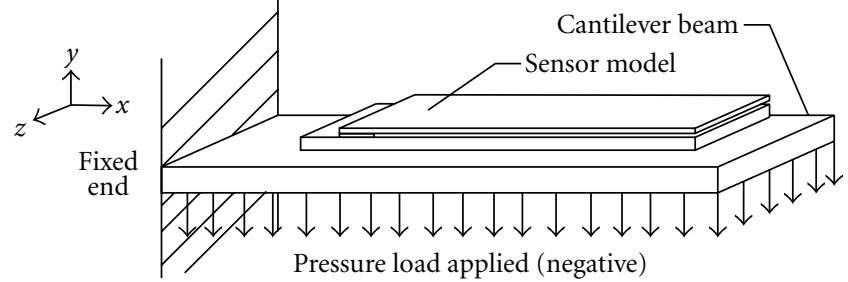

FIGURE 4: Boundary condition applied in finite element analysis.

TABle 4: Simulation results for different electrode gaps.

\begin{tabular}{lccc}
\hline Gap, $\mu \mathrm{m}$ & 1.5 & 3.0 & 5.0 \\
Nominal capacitance $($ at $0 \mu \varepsilon), \mathrm{pF}$ & 117.2815 & 58.8272 & 35.4343 \\
Capacitance at $1000 \mu \varepsilon, \mathrm{pF}$ & 61.3576 & 34.4750 & 22.8095 \\
Sensitivity $(0-1000 \mu \varepsilon), \mathrm{pF} / \mu \varepsilon$ & 0.0559 & 0.0244 & 0.0126 \\
Maximum percentage difference, \% & 5.00 & 4.49 & 3.88 \\
Average percentage difference, $\%$ & 2.82 & 2.10 & 2.17 \\
\hline
\end{tabular}

For dielectric coverage analysis, the total capacitance was given by

$$
\begin{gathered}
C_{T}=C_{1}+C_{3}, \quad \text { where } C_{1}=\frac{\varepsilon_{0} \varepsilon_{r} A_{1}}{d} ; \quad C_{3}=C_{\text {air }}+C_{\mathrm{SiO}_{2}}, \\
C_{\text {air }}=\frac{\varepsilon_{0} \varepsilon_{r} A_{2}}{d+D_{\text {air }}}, \\
\frac{1}{C_{\mathrm{SiO}_{2}}}=\frac{1}{\varepsilon_{0} \varepsilon_{r} A_{\mathrm{SiO}_{2}} /\left(d_{\mathrm{air}}+D_{\mathrm{SiO}_{2}}\right)}+\frac{2}{\varepsilon_{0} \varepsilon_{r} A_{\mathrm{SiO}_{2}} / d_{\mathrm{SiO}_{2}}}, \\
\text { Sensitivity }=\frac{\Delta C}{\Delta \varepsilon} .
\end{gathered}
$$

\section{Results and Discussions}

Simulation was carried out using MEMS conventional finite element software, CoventorWare 2008. The boundary conditions applied for the simulation were exactly similar to the analytical method and hence a similar bending mechanism is expected, with minimum errors and uncertainties. Figure 4 shows the boundary conditions applied in the finite element study. The sensor was placed on the cantilever beam having one end fixed, and a distributed load applied uniformly along the bottom surface of the cantilever beam.

4.1. Electrode Gap (Anchor Thickness). The effect of varying electrode gap is studied. Based on the sensor design, three different gap values, $1.5 \mu \mathrm{m}, 3 \mu \mathrm{m}$, and $5 \mu \mathrm{m}$, are selected. The anchor length was maintained constant at $1 \mathrm{~mm}$. Figure 5 shows the results of electrode gap comparison for the analysis study.

The electrode gap of $1.5 \mu \mathrm{m}$ demonstrated higher capacitance output, followed by the $3 \mu \mathrm{m}$ and $5 \mu \mathrm{m}$ gap. Table 4 shows the results for sensitivity, nominal capacitance, and the average and maximum percentage difference between calculation and simulation results.

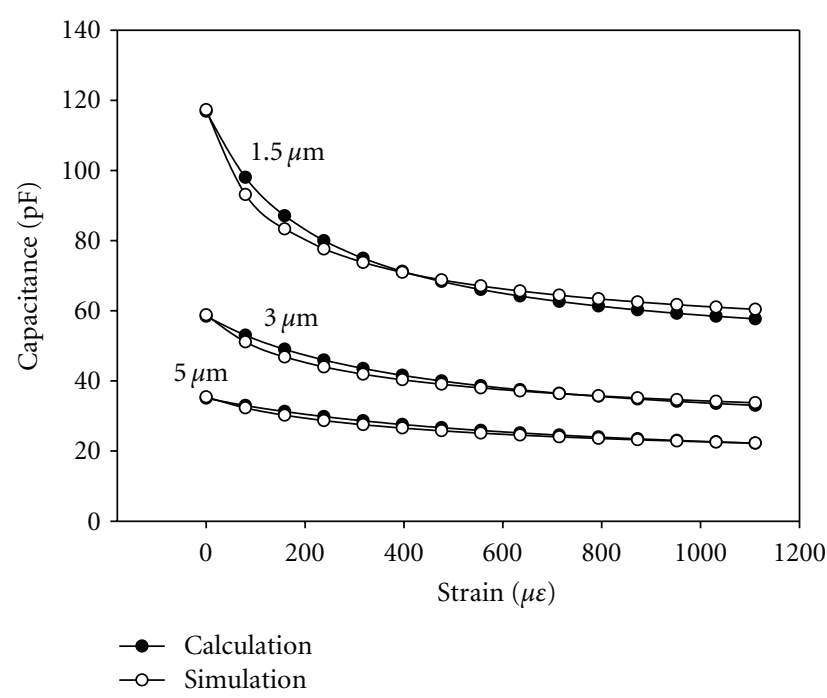

FIGURE 5: Capacitance output for $1.5 \mu \mathrm{m}, 3 \mu \mathrm{m}$, and $5 \mu \mathrm{m}$ electrodes gap.

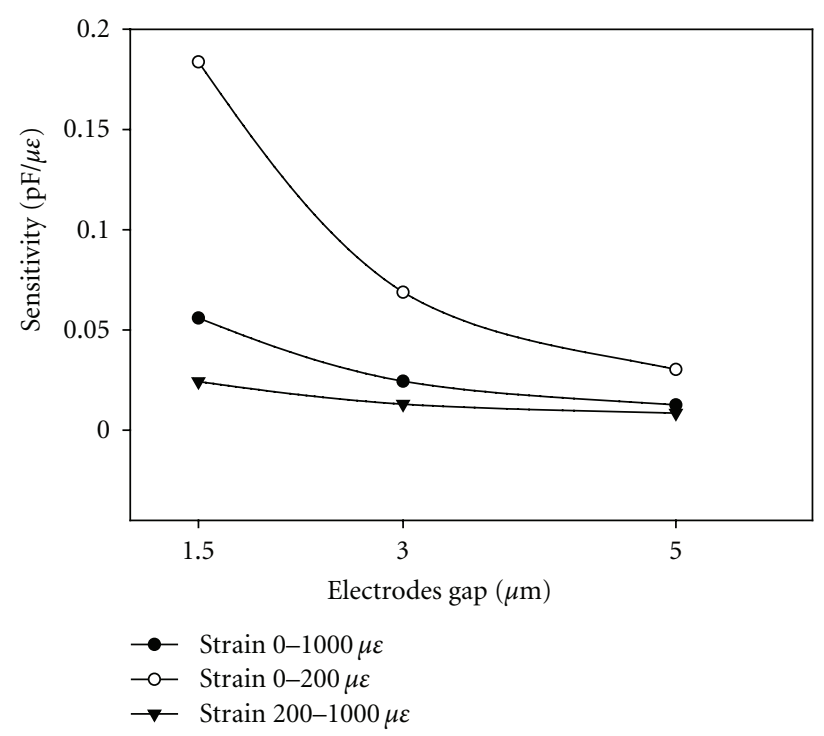

Figure 6: Sensitivity comparison of different electrodes gap at different strain values.

The lowest gap $1.5 \mu \mathrm{m}$ exhibits the highest sensitivity between 0 and $1000 \mu \varepsilon$, followed by $3 \mu \mathrm{m}$ and $5 \mu \mathrm{m}$. The sensitivity increased by $129 \%$ when the gap was reduced to half of its original length. From Figure 6 it can be inferred that the capacitance change was significant when load was applied between strains 0 to $200 \mu \varepsilon$. In this region the sensor was very sensitive to the strain changes. The variation of sensitivity for different region of strain can be observed in Figure 6.

4.2. Anchor Length. Another parameter that was considered for this study was the length of the anchor. The length of anchor determines the overall electrode gap opening when bending occurred. Longer the anchors, higher the nominal 


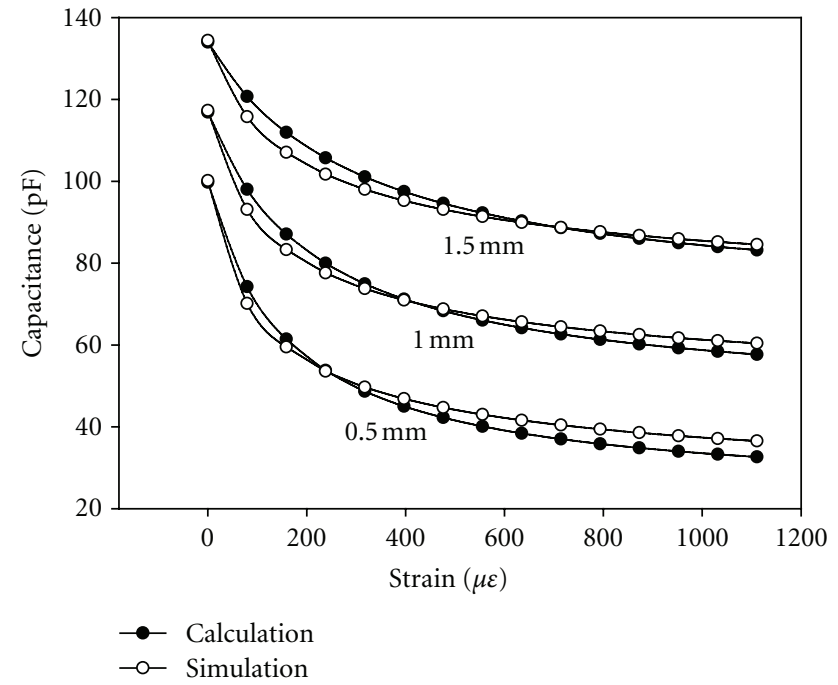

Figure 7: Capacitance output with strain for anchor length of $0.5 \mathrm{~mm}, 1.0 \mathrm{~mm}$, and $1.5 \mathrm{~mm}$.

TABLE 5: Analysis outcome for different anchor length.

\begin{tabular}{lccc}
\hline Anchor length, $\mathrm{mm}$ & 0.5 & 1.0 & 1.5 \\
Nominal capacitance (at $0 \mu \varepsilon$ ), pF & 100.1602 & 117.2815 & 134.4027 \\
Capacitance at $1000 \mu \varepsilon, \mathrm{pF}$ & 37.3074 & 61.3576 & 84.7248 \\
Sensitivity $(0-1000 \mu \varepsilon), \mathrm{pF} / \mu \varepsilon$ & 0.0628 & 0.0559 & 0.0497 \\
Maximum percentage difference, \% & 11.91 & 5.00 & 4.35 \\
Average percentage difference, \% & 6.76 & 2.82 & 1.75 \\
\hline
\end{tabular}

capacitance, but a longer anchor gives a lower capacitance drop when bending occurs. Three different anchor lengths, $0.5 \mathrm{~mm}, 1.0 \mathrm{~mm}$, and $1.5 \mathrm{~mm}$, were used to study the capacitance output of the sensor. The initial gap of the electrode was set at $1.5 \mu \mathrm{m}$. Figure 7 shows the anchor length results when bending occurred.

The results with $1.5 \mathrm{~mm}$ of anchor length showed highest capacitance output. This can be attributed to larger dielectric area present. The dielectric area with a dielectric coefficient of 3.9 showed increase in the capacitance output. Despite this, $1.5 \mathrm{~mm}$ anchor length displayed lower sensitivity when compared to others. However, $0.5 \mathrm{~mm}$ anchor length had lowest capacitance output but showed the highest sensitivity. Table 5 shows the analysis results for various anchor lengths.

The sensitivity of the sensor decreased with increase in the anchor length. When the length of the anchor was small, the movable area of the sensor increased. This led to an increase in the electrode gap opening during bending and resulted in the higher capacitance drop and also the sensitivity of the sensor. These results with capacitance output were similar to that obtained by varying the electrode gap. The change in capacitance decreased when strain was increased; however the sensor showed a greater change in capacitance in the strain range of $0-200 \mu \varepsilon$. Figure 8 shows the sensitivity of the sensor for various strain values.
TABLe 6: Simulation results for different dielectric coverage.

\begin{tabular}{lccc}
\hline Dielectric percentage, $\%$ & 33 & 66 & 100 \\
Nominal capacitance (at $0 \mu \varepsilon$ ), pF & 185.3399 & 253.5873 & 321.5873 \\
Capacitance at $1000 \mu \varepsilon, \mathrm{pF}$ & 62.8281 & 62.8281 & 70.2733 \\
Sensitivity $(0-1000 \mu \varepsilon), \mathrm{pF} / \mu \varepsilon$ & 0.1225 & 0.1906 & 0.2513 \\
Maximum percentage difference, \% & 10.22 & 13.04 & 15.98 \\
Average percentage difference, \% & 4.84 & 8.90 & 11.84 \\
\hline
\end{tabular}

4.3. Dielectric Coverage. The dielectric material study covering $33 \%, 66 \%$, and $100 \%$ of the electrode area was undertaken. The $100 \%$ coverage area gave the highest capacitance output. The $33 \%$ and $66 \%$ coverage area was located near the opening end of the sensor. While bending, opening end of the sensor would have highest gap change, and therefore by locating the dielectric material in this location, the change in capacitance can be expected to be higher. The anchor length was set at $1 \mathrm{~mm}$ and the electrodes gap of $1.5 \mu \mathrm{m}$ was utilized for this study. Figure 9 shows the results for each of the dielectric covers employed in this study.

The presence of dielectric led to a significant increase in the capacitance output. During bending, the capacitance output dropped from $75 \%$ to $82 \%$ for a total capacitance change between 0 and $100 \mu \varepsilon$. Most of the capacitance change occurred in this region. The capacitance output between 100 and $1000 \mu \varepsilon$ for $66 \%$ and $33 \%$ of dielectric coverage, was almost identical. Table 6 summarizes the results for dielectric coverage studies.

The sensitivity and capacitance output increased with the dielectric coverage. It was observed that, reducing dielectric material or locating it at the opening end of the sensor beam does not increase the sensitivity of the sensor. Figure 10 shows the sensitivity for all the three dielectric coverage, compared at different strain ranges.

4.4. Simulation Analysis Discussion. Simulation study was carried out involving three parameters in order to study the sensor response to bending strain in terms of capacitance output and sensitivity. Figure 11 shows the nominal capacitance of the sensor when different gap and different anchor length were applied. It is evident from these results that by reducing electrode gap, increasing anchor length and increasing dielectric coverage would in turn lead to increase in capacitance output.

On reducing the electrode gap, a nonlinear increase in the nominal capacitance was observed. The gap represents a significant factor in the capacitance output of the sensor. However, a very small gap can cause the electrodes to touch if the electrostatic force applied was strong enough. Therefore, for a $1.5 \mu \mathrm{m}$ electrode gap, the highest voltage that can be applied for the capacitance reading was $1 \times 10^{-6} \mathrm{~V}$. A higher voltage can lead to sensor deflection which can change the capacitance reading even before the application of bending strain. Figure 12 illustrates the deflection of the sensor and the capacitance change due to electrostatic force. The deflection occurred at the top electrode of the sensor as shown in Figure 13. The deflection of the top layer of 


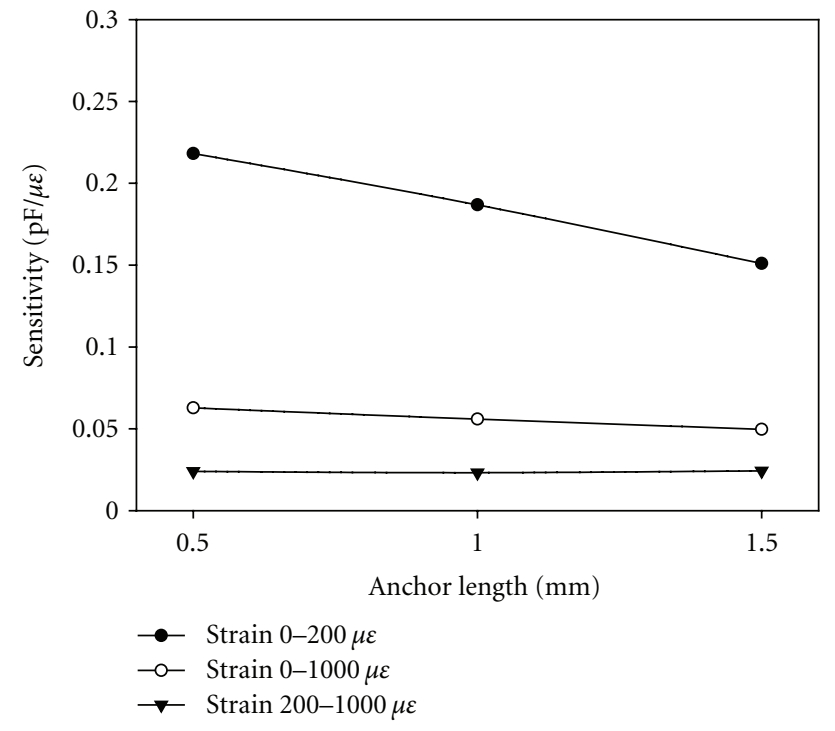

FIgURE 8: Sensitivity comparison for anchor length at different strain value.

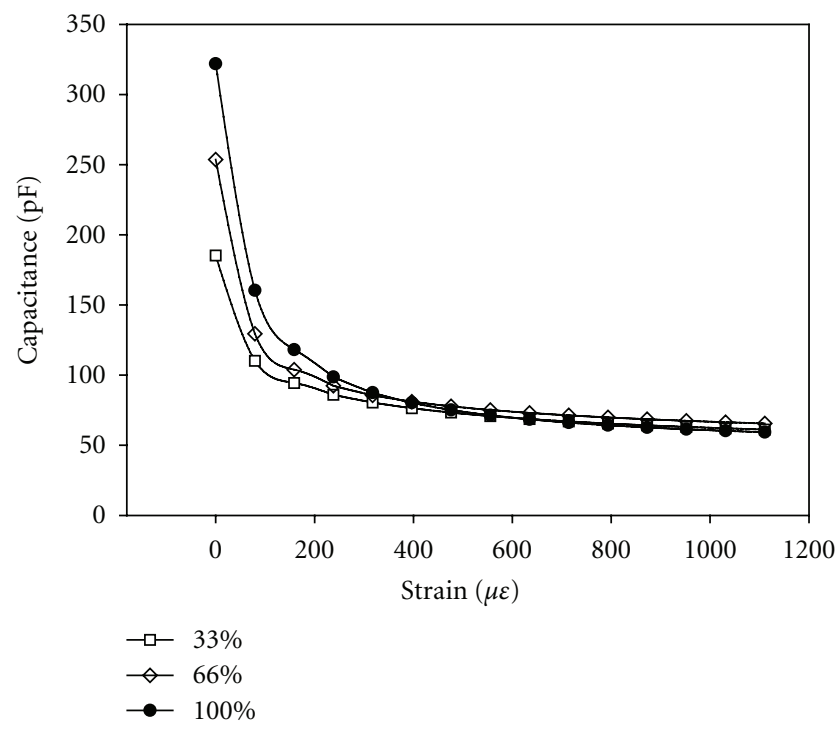

Figure 9: Comparison of simulation results.

the sensor decreased when the voltage decreased. For a voltage of $0.1 \mathrm{~V}$, a very high capacitance value of $117.305 \mathrm{pF}$ was observed as a result of deflection in the reduced gap. However, when the voltage applied was $1 \times 10^{-4} \mathrm{~V}$, the change in capacitance was very low and when the voltage applied was $1 \times 10^{-6} \mathrm{~V}$, the change in capacitance was almost negligible.

With respect to the anchor length, changes in the nominal capacitance are of linear order. The anchor basically is composed of silicon dioxide, for which the coefficient of dielectric material was 3.9. For a nominal capacitance, increasing the length of the anchor would also increase the dielectric material coverage between the electrodes. So, the nominal capacitance would increase in the same manner for both anchor length analysis and dielectric coverage analysis.

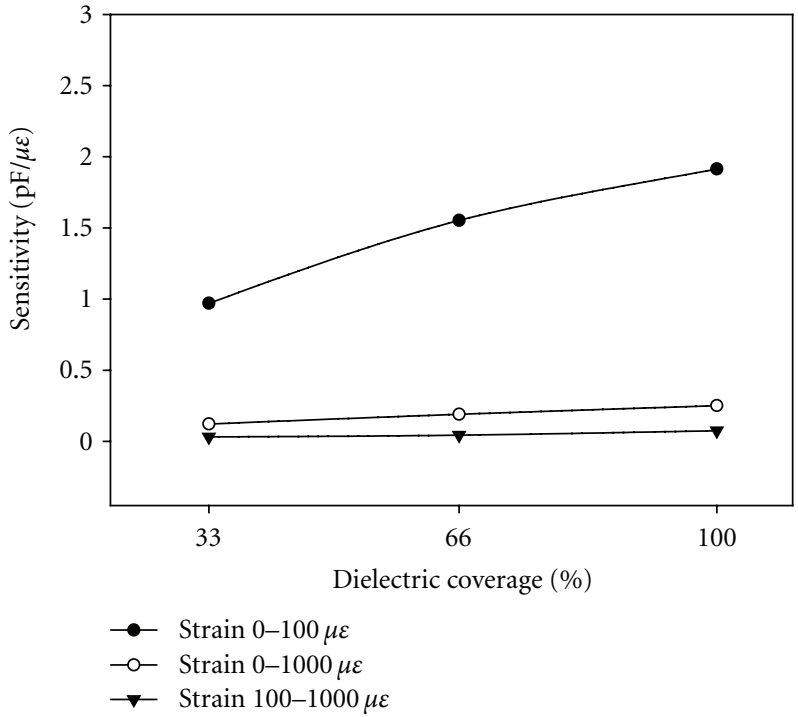

FIGURE 10: Sensitivity comparisons at different strain range for all the three dielectric coverage.

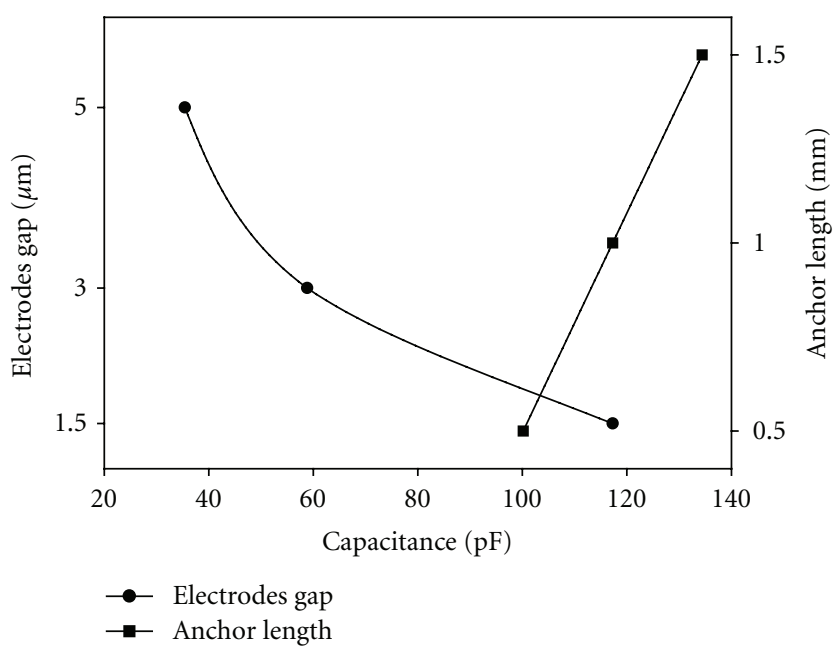

FIGURE 11: Nominal capacitance comparisons for electrode gap and anchor length.

During cantilever beam bending, the capacitance output would follow nonlinear pattern with the strain. Similarly, the capacitance drop was different for other variations of electrode gap, anchor length, and total dielectric coverage on the movable area. The capacitance drop was the result of the change in electrode gap at the movable part of the sensor. When bending increased, the gap also increased, because of which the capacitance output dropped. Thus the capacitance change corresponding to the bending strain can be evaluated using the sensitivity value. The sensitivity of the sensor increased when the electrode gap was reduced. During bending, the gap between the electrodes increased. The electrode gap which was small initially would increase significantly with bending, in comparison to the one with bigger initial electrode gap for the same bending strain value. 


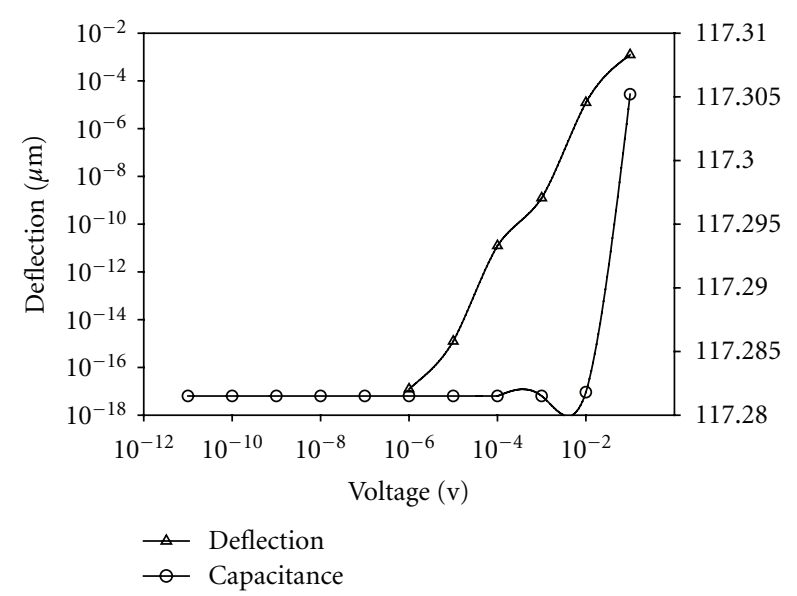

Figure 12: Voltages and the corresponding deflection and capacitance values.

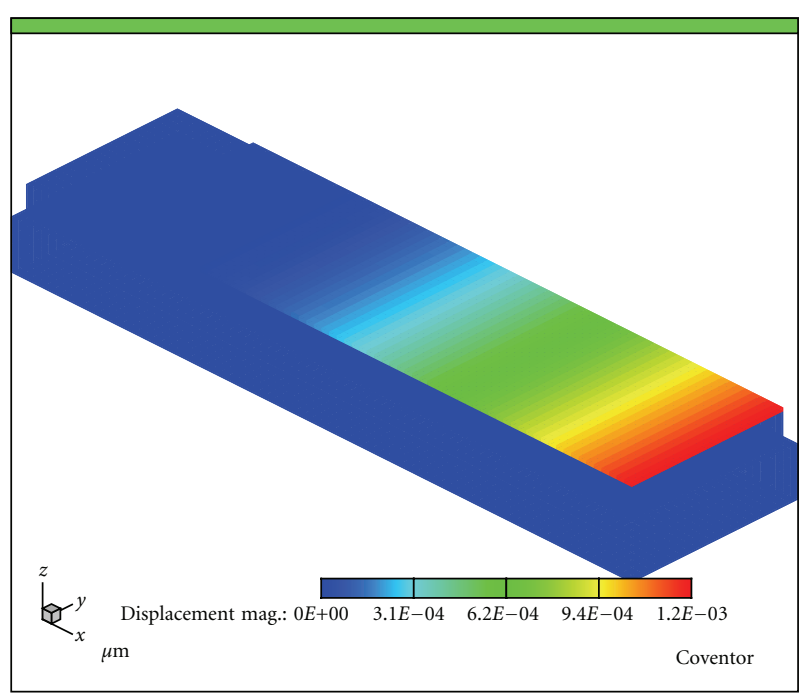

FIgURE 13: Top electrode deflection of the sensor when $0.1 \mathrm{~V}$ is applied.

The greater percentage of gap increment led to increase in the capacitance drop and also the sensitivity of the sensor. This is further demonstrated in Figure 14 which shows the average value of gap percentage increment for different electrodes gap.

In case of anchor length analysis, a completely different sensitivity performance was observed. The sensitivity of the sensor decreased when the anchor length was increased, even though the nominal capacitance was larger for the longer anchor length. This capacitance drop can be attributed to the movable part of the sensor. Despite the fact that longer anchor length gave a higher capacitance output, the movable part of the sensor was shorter. A shorter movable electrode results in smaller capacitance drop when bending occurred and thus reduced the sensitivity of the sensor. Figure 15 shows the comparison for the average percentage drop of capacitance output at the movable part of the sensor electrodes for different anchor length. Anchor length

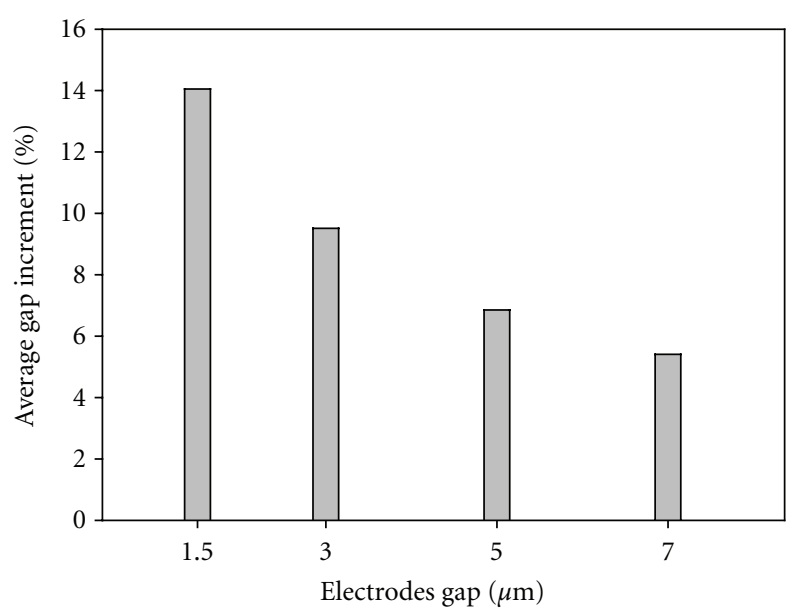

FIGURE 14: Average gap percentage increment for different electrode gap.

of $0.5 \mathrm{~mm}$ showed a greater average percentage drop in capacitance. This can be explained due to the longer length of movable part when bending occurred.

The last sensitivity analysis was that of dielectric coverage. The large portion of dielectric coverage would increase the capacitance output and sensitivity of the sensor. $100 \%$ dielectric coverage displayed the maximum sensitivity. However, the $33 \%$ and $66 \%$ of dielectric coverage did not increase the sensitivity as expected. During the bending process, the electrode gap from the extreme free end of the electrode towards the anchor is reduced to a minimum. Thus, by placing the dielectric material having dielectric constant of 3.9 , at the free end of the electrodes and covering $33 \%$ or $66 \%$, the capacitance drop when bending occurred was expected to be higher. However, the results showed a different behaviour. From the study, it was found that the sensitivity of $33 \%$ and $66 \%$ did not increase due to the anchor capacitance. The anchor which was made from silicon dioxide contributed $46.042 \mathrm{pF}$ of capacitance. This capacitance value did not change with bending strain because no gap increment occurred in this area. Thus, the total capacitance which includes the anchor capacitance reduced the total capacitance drop of the sensor and also the sensitivity of $33 \%$ and $66 \%$ dielectric coverage sensor. However, the average percentage capacitance drop for $33 \%$ and $66 \%$ which occurred at the movable part of the electrode was higher when compared to $100 \%$ coverage. Figure 16 shows the average percentage capacitance drop comparison at the movable electrode area for all dielectric coverage.

The 33\% dielectric coverage showed a higher capacitance drop, followed by $66 \%$ and $100 \%$ coverage at movable electrodes of the sensor. This shows that if the anchor material was to be substituted with a lower dielectric constant, it can reduce the capacitance of the anchor; thereby the sensitivity of $33 \%$ coverage can be optimized and a higher value than $100 \%$ dielectric coverage was achievable.

The overall sensitivity performance of the sensor indicates that the sensor was very sensitive at the early stages of bending strain development. The electrode gap and anchor 


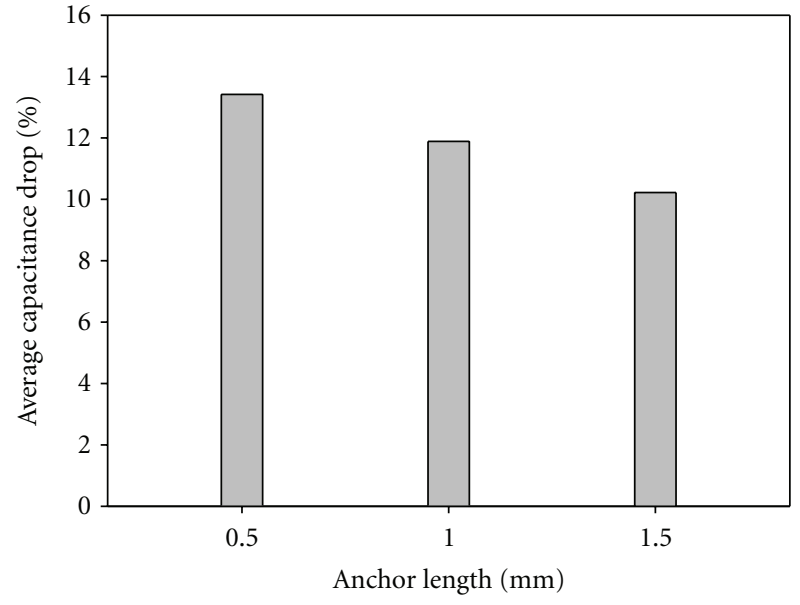

FIGURE 15: Average percentage of capacitance drop for different anchor length.

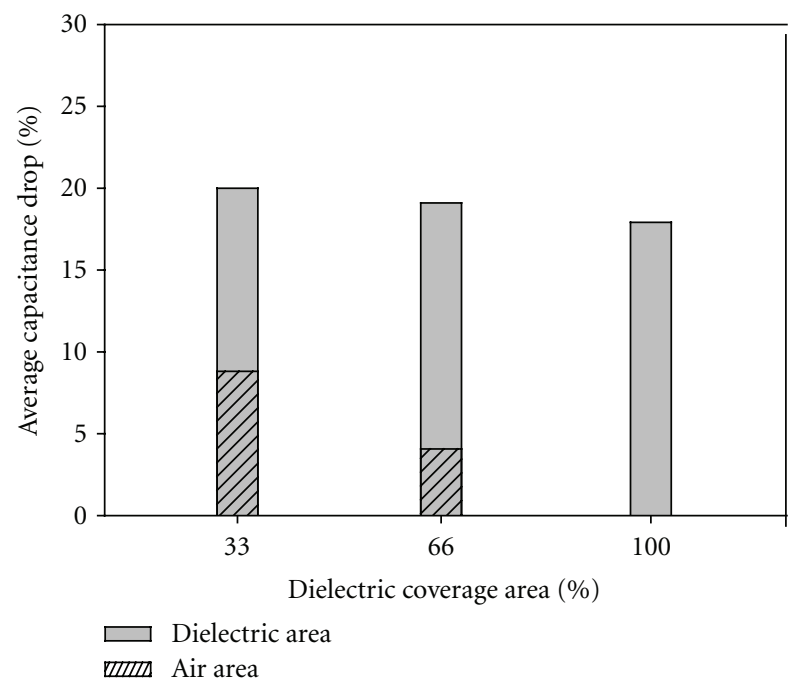

FIgURE 16: Average capacitance drop for dielectric coverage area.

length analysis study showed that the sensor had a higher sensitivity value ranging between 0 and $200 \mu \varepsilon$, and the sensitivity remained the same on further increase in the strain beyond $200 \mu \varepsilon$. On the other hand the dielectric coverage analysis study showed that the highest sensitivity was between 0 and $100 \mu \varepsilon$. This sensitivity performance can be attributed to the percentage gap difference when bending occurred. At the beginning of the bending process, the percentage gap increment was higher, allowing a higher capacitance drop. Later as the bending increased further, the percentage gap increment was reduced leading to lower capacitance drop and lower sensitivity. This aspect of percentage gap increment with bending strain can be observed for all the cases in Figure 17.

From the figure it is evident that the 33\% and 66\% gap increment for air part was lesser because it was located near the anchor which facilitated only a small opening. The initial gap for dielectric area with $33 \%, 66 \%$, and $100 \%$ can

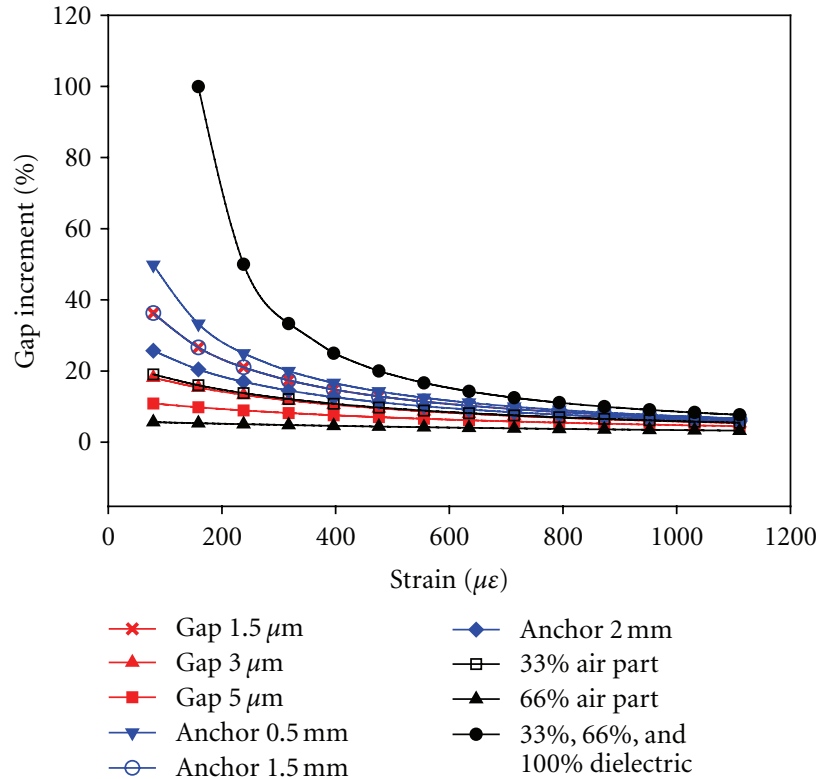

Figure 17: Percentage of gap increment for all cases.

be assumed to be $0 \mu \mathrm{m}$. Thus, during the start of bending process, the percentage gap increment was very high leading to higher sensitivity. It is for this reason the sensitivity between 0 and $100 \mu \varepsilon$ was very high for dielectric coverage sensor.

Figure 18 shows the contours for strain distribution when the sensor was attached to the loaded beam. The strain showed the highest value at the end of anchor region. It is clear from the figure that the stress was concentrated at this region during the bending process. Observations were obtained by Lin et al. [5] who found that the maximum strain before fracture for silicon was around $1800 \mu \varepsilon$. Therefore on further loading anchor region of the sensor would fail due to fracture.

\section{Conclusions}

Simulation study was carried out to understand the MEMS capacitive bending strain sensor based on double layer cantilever design of behaviour and its performance on application of bending strain. The capacitance output, sensitivity performance evaluation by manipulating the electrodes gap, anchor length, and dielectric coverage were carried out and validated using analytical methods and the results showed that nominal capacitance and sensitivity of the sensor increased when the gap between the electrodes was reduced. In addition, it was found that sensitivity of the sensor increased with a shorter anchor length as a result of higher percentage gap opening during the bending process. The 100\% dielectric coverage using silicon dioxide material demonstrated highest sensitivity. Meanwhile the sensitivity of $33 \%$ and $66 \%$ dielectric coverage can be optimized using dielectric material having lower dielectric constant than the sensor anchor. The overall sensor performance indicated that the sensor can be optimized by reducing the electrode 


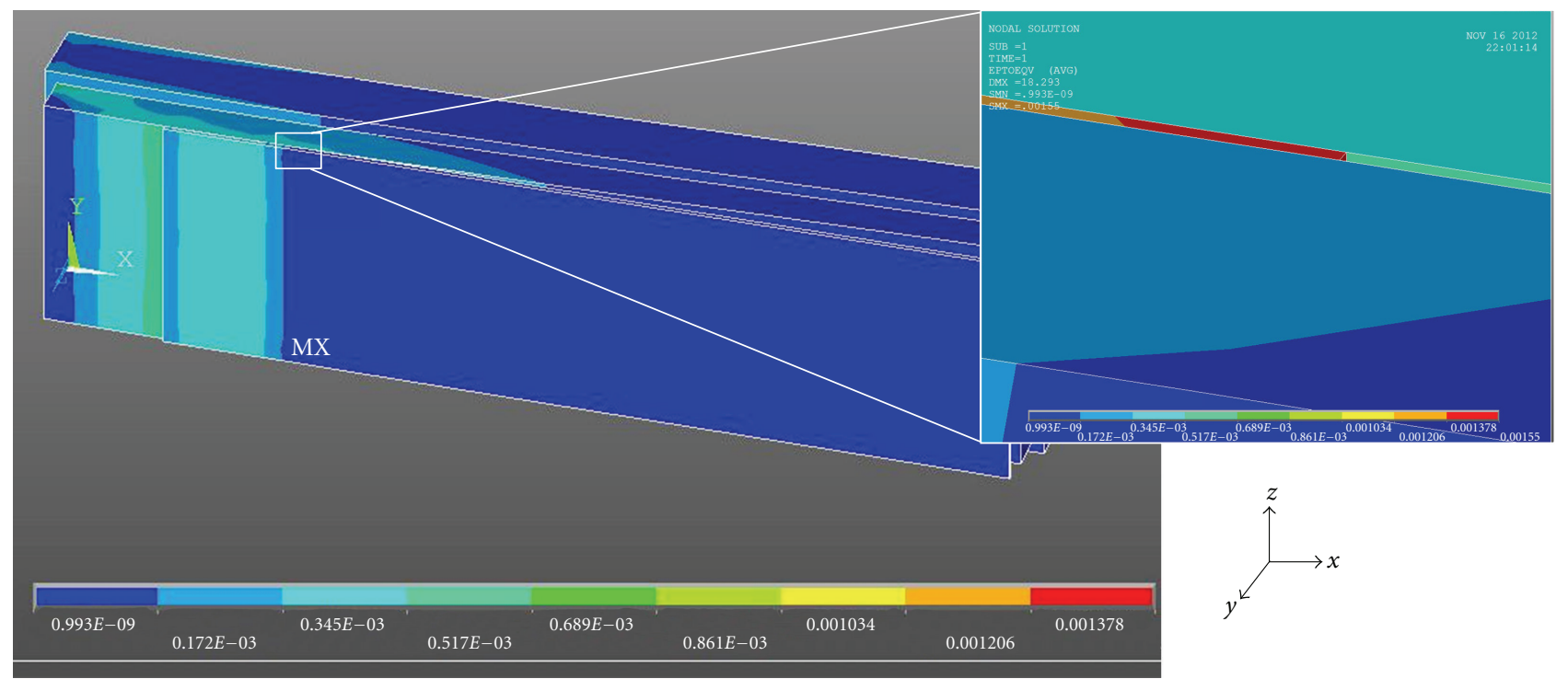

Figure 18: Figure shows the strain distribution when load was applied (Ansys 10.0).

gap, reducing the anchor length, and on application of dielectric material. It was concluded that a very small voltage of $1 \times 10^{-6}$ volt was preferable for capacitance reading of the sensor as it helped to overcome the electrostatic forces developed. However, while designing any sensor, factors such as fabrication abilities and electrostatic charges which add to the limitation of the sensor performances should also be considered.

\section{Nomenclature}

$\varepsilon_{0}$ : $\quad$ Relative permittivity of free space

$$
\left(8.85 \times 10^{-12} \mathrm{~F} \cdot \mathrm{m}^{-1}\right)
$$

$\varepsilon_{r}: \quad$ Dielectric constant

A: $\quad$ Overlap area of the electrode

$d$ : $\quad$ Gap of the electrode

$\sigma_{\max }: \quad$ The maximum normal stress in the member

M: $\quad$ The resultant internal moment

I: $\quad$ The moment of inertia of the cross-sectional area computed about the neutral axis

$y_{\max }: \quad$ The farthest point perpendicular to neutral axis

$\sigma: \quad$ Normal stress in the member

E: Young's Modulus

$\varepsilon: \quad$ Strain

$C_{T}: \quad$ Total capacitance

$C_{1}$ : Capacitance of anchor $\left(\mathrm{SiO}_{2}\right)$

$\mathrm{C}_{2}$ : Capacitance of air gap

$C_{3}$ : $\quad$ Multilayer dielectric capacitance

$C_{\text {air }}: \quad$ Capacitance of air area (with dielectric)

$C_{\mathrm{SiO}_{2}}$ : Capacitance of dielectric area

$\Delta C: \quad$ Capacitance change between two points of strain

$C_{0}: \quad$ Capacitance at $0 \mu \varepsilon$

$C_{1000 \mu \varepsilon}$ : Capacitance at $1000 \mu \varepsilon$

$\Delta \varepsilon: \quad$ Strain change at two points

$A_{1}: \quad$ Anchor $\left(\mathrm{SiO}_{2}\right)$ area

$A_{2}$ : $\quad$ Air gap area (no dielectric)
$A_{\text {air }}: \quad$ Air gap area (with dielectric)

$A_{\mathrm{SiO}_{2}}:$ Dielectric area

$d_{\text {air }}:$ Initial gap (dielectric area)

$d_{\mathrm{SiO}_{2}}$ : Dielectric gap

$D$ : $\quad$ Average gap of the electrodes opening during bending (no dielectric)

$D_{\text {air }}$ : Average gap of the electrodes opening during bending (with dielectric)

$D_{\mathrm{SiO}_{2}}$ : Average gap of the electrodes opening during bending at the dielectric area.

\section{Acknowledgments}

The work was supported by Research University Grant, Universiti Sains Malaysia, under Grant 1001/PMEKANIK/ 814099 and Graduate Research Fund, under Grant 308/AIPS/ 415401. The authors also express their gratitude for the facilities and opportunities provided by Collaborative Microelectronic Design Excellence Centre USM (CEDEC) in undertaking this project.

\section{References}

[1] R. Puers, "Capacitive sensors: when and how to use them," Sensors and Actuators A, vol. 37-38, pp. 93-105, 1993.

[2] R. Matsuzaki and A. Todoroki, "Wireless flexible capacitive sensor based on ultra-flexible epoxy resin for strain measurement of automobile tires," Sensors and Actuators A, vol. 140, no. 1, pp. 32-42, 2007.

[3] M. Suster, J. Guo, N. Chaimanonart, W. H. Ko, and D. J. Young, "A high-performance MEMS capacitive strain sensing system," Journal of Microelectromechanical Systems, vol. 15, no. 5, pp. 1069-1077, 2006.

[4] J. Aebersold, K. Walsh, M. Crain et al., "Design and development of a MEMS capacitive bending strain sensor," Journal of Micromechanics and Microengineering, vol. 16, no. 5, pp. 935$942,2006$. 
[5] J. T. Lin, K. W. Walsh, D. Jackson et al., "Development of capacitive pure bending strain sensor for wireless spinal fusion monitoring," Sensors and Actuators A, vol. 138, no. 2, pp. 276287, 2007.

[6] B. E. Finneson, Low Back Pain, J.B. Lippincott Company, Philadelphia, Pa, USA, 2nd edition, 1981.

[7] A. Nather, Bone Graft and Bones Substitutes: Basic Sciences and Clinical Application, World Scientific, Singapore, 2005.

[8] M. Kanayama, B. W. Cunningham, J. C. Weis, L. M. Parker, K. Kaneda, and P. C. McAfee, "Maturation of the posterolateral spinal fusion and its effect on load- sharing of spinal instrumentation," Journal of Bone and Joint Surgery —Series A, vol. 79, no. 11, pp. 1710-1720, 1997.

[9] H. Gibson, Measurement and finite element modeling of spinal rod strain [M.S. thesis], Department of Mechanical Engineering, University of Louisville, 2002.

[10] R. C. Hibeler and S. C. Fan, Statics and Mechanics of Materials, Pearson Education, Singapore, SI edition, 2004.

[11] M. I. A. Mokti, I. A. Rahim, A. A. Manaf, O. B. Sidek, and M. A. B. Miskam, "Design and simulation of a MEMS capacitive bending strain sensor using dielectric materials for spinal fusion monitoring," in Proceedings of the IEEE Regional Symposium on Micro and Nanoelectronics (RSM), pp. 329-333, Kota Kinabalu Sabah, Malaysia, 2011. 

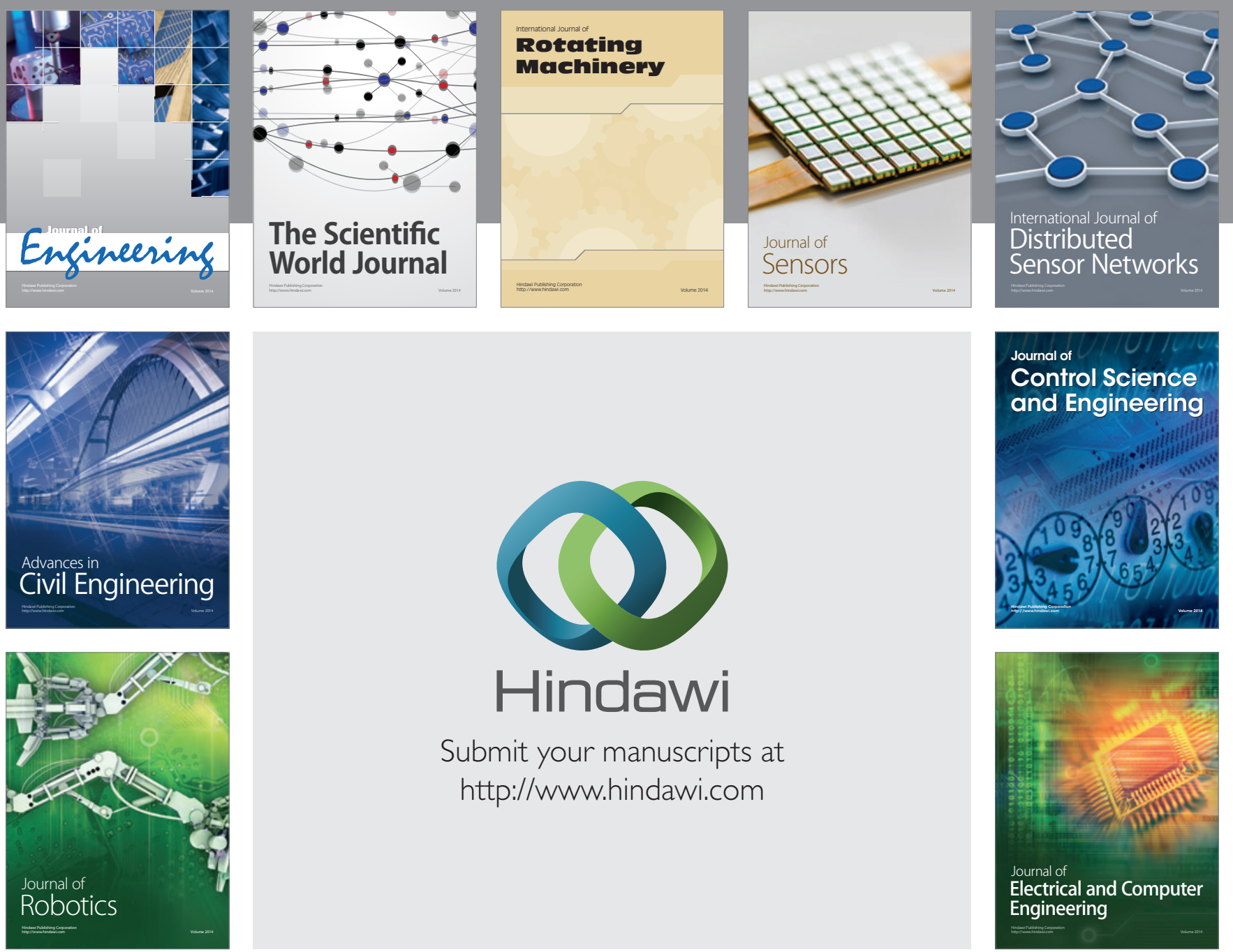

Submit your manuscripts at

http://www.hindawi.com
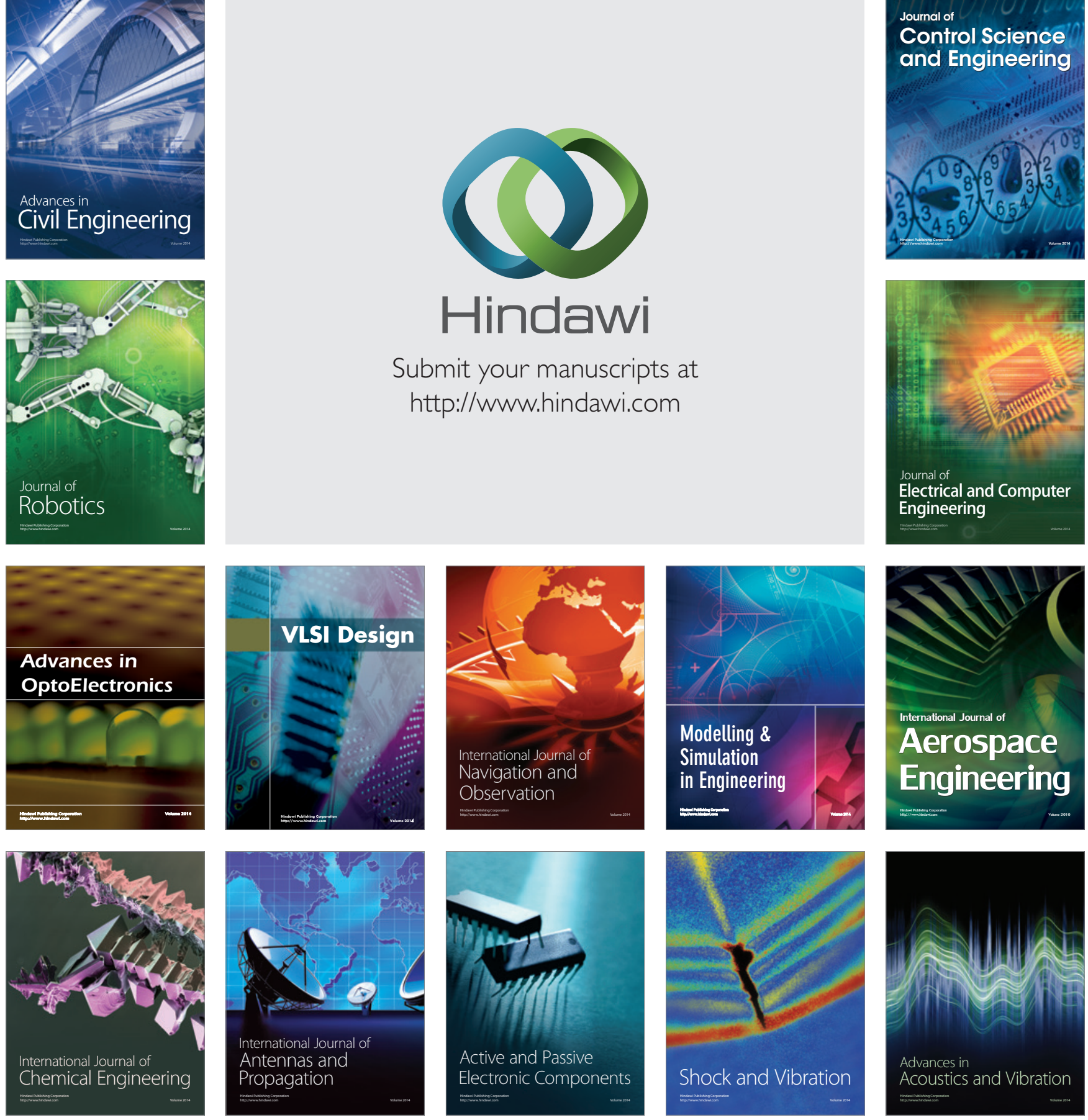